\title{
Reliability checking for GNSS baseline and network processing
}

Andreas Wieser

\section{GPS Solutions (2004) DOI 10.1007/ s10291-004-0091-9}

Due to an unfortunate error, the addresses of the author were mixed up and are published correct here.

The online version of the original article can be found at http:// dx.doi.org/10.1007/s10291-004-0091-9

Published online: 23 July 2004

(c) Springer-Verlag 2004

A. Wieser

Engineering Geodesy and Measurement Systems,

Graz University of Technology, Steyrergasse 30,

$8010 \mathrm{Graz}$, Austria

E-mail: andreas.wieser@tugraz.at

Tel.: +43-316-8736323

Fax: $+43-316-8736820$

Present address:

Department of Geomatics Engineering

University of Calgary, 2500 University Drive NW,

Calgary, AB, T2N 1N4, Canada 